\title{
INVESTIGATIONS OF ELECTRON BEAM CHARACTERISTICS USING THE ACCELERATOR BASED ON A MAGNETRON GUN WITH A SECONDARY-EMISSION CATHODE
}

\author{
N.I. Ayzatsky, A.N.Dovbnya, V.V.Zakutin, \\ N. G. Reshetnyak, V. N. Boriskin, N.A. Dovbnya, \\ V. P. Romas'ko, I. A. Chertishchev
}

National Science Center «Kharkov Institute of Physics and Technology», Kharkov, Ukraine

\begin{abstract}
The reliability and service life of accelerating installations are substantially determined by the lifetime of electron sources. The accelerator under consideration comprises, as an electron source, a magnetron gun with a channel-free cold secondary-emission cathode in crossed fields $[1,2]$. In the present work the data of electron beam parameters obtained in the accelerator based on the magnetron gun with a secondary-emission cathode are given and the possibilities of its use for secondary purposes are suggested.
\end{abstract}

Дано описание ускорителя электронов прямого действия, в котором в качестве источника частиц используется магнетронная пушка с вторично-эмиссионным катодом. Проведено исследование параметров электронного пучка для диапазона напряжения от 20 до 100 кВ при длительности импульса от 6 до 50 мкс и частоте следования импульса 3-15 Гц. Исследовано время нарастания тока пучка, его стабильность и азимутальная однородность при различных распределених магнитного поля. Проведено измерение ширины зоны формирования электронного пучка по магнитному полю. Изучены размеры пучка на мишени в зависимости от магнитного поля. Были исследованы три режима генерации пучка (открытый, промежуточный и закрытый), отличающиеся направлением электронного тока. В одном из режимов была получена энергия ускоренных электронов $\sim 100$ кэВ, ток пучка $\sim 110$ А, плотность мощности на мишени $\sim 3$ МВт/см². Проведено облучение мишени из инструментальной стали и титана, получено увеличение твердости поверхности в 2 раза.

PACS: 29.27.Fh

\section{DESCRIPTION OF THE ACCELERATOR AND RESEARCH TECHNIQUES}

The electron accelerator (Fig. 1) comprises the following main units: high-voltage pulse generator 1 ; electron source 2 with secondary-emission cathode and anode placed in the vacuum chamber; solenoid 5 creating a longitudinal magnetic field; target device with eightsegment Faraday cup 3; computer-aided measuring system 4 for measurements of electron beam parameters. 


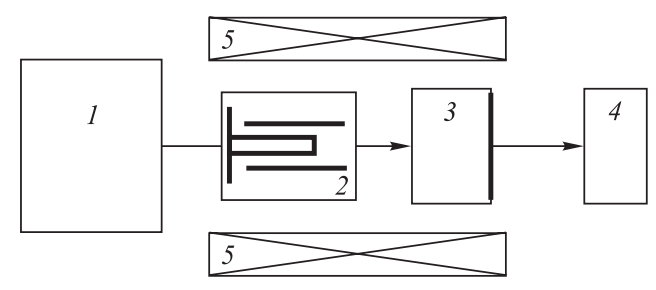

Fig. 1. Schematic representation of the accelerator

The data of beam parameter measurements were processed and displayed by the computeraided measuring system [3]. The transverse beam size and the radial beam-current distribution along the radius were determined using the beam prints on the targets made of different materials.

\section{EXPERIMENTAL RESULTS AND DISCUSSION}

One of the main problems arising during operation of the electron accelerators based on the magnetron gun is to achieve the operating conditions with a given energy and a power density on the target. For the beam parameters be obtained in a wide energy range it is necessary to use several geometries of magnetron guns.

Experimental investigations on the formation and measurement of the electron beam produced by the accelerator were carried out. The dependence of the current, current rise time, azimuthal homogeneity, time stability and beam sizes on the voltage amplitude and magnetic field distribution along the gun axis was studied.

At the first stage, the investigations using the magnetron gun with a copper cathode (of diameter $40 \mathrm{~mm}$ ) and a stainless steel anode (of internal diameter $70 \mathrm{~mm}$ ) were carried out in the voltage range from 30 to $60 \mathrm{kV}$.

Figure 2 shows the distribution of beam charges from each of the eight Faraday cup segments along the azimuth for two cases. It is seen from the figure that the beam charge value along the azimuth (in panel $a$ ) in the falling magnetic field is practically constant (coefficient of azimuthal beam homogeneity $K=1.08$ ) and in the uniform field $( \pm 7 \%)$ it is changing (in panel $b K=1.25$ ) [3]. The time of beam pulse rising is $3-10 \mathrm{~ns}$. The short-time stability of the total beam current and that of its azimuthal segments is from 2 to $4 \%$ and in the case of the instable voltage pulse amplitude it is $\sim 2 \%$. The long-term stability during 4 hours was from 3 to $5 \%$.

The measurements of the electron beam sizes on the aluminum target placed within the Faraday cup region were performed for the cases of rising and falling magnetic field.

Figure 3 presents, for these two cases, the beam prints obtained on the same target. The computer-aided processing of beam prints has shown that the electron beam homogeneity by the beam radius is $\pm 17 \%$.

The second stage of investigations (cathode diameter of $40 \mathrm{~mm}$ and anode diameter of $78 \mathrm{~mm}$ ) was aimed at obtaining the maximum electron beam parameters in the falling magnetic field at a voltage amplitude of $\sim 100 \mathrm{kV}$. It has been found that the beam current reaches $\sim 100 \mathrm{~A}$ (Fig. 4) and the beam generation zone over the magnetic field is $\Delta H \sim 300$ Oe. A considerable width of the beam generation zone, $\Delta H$, is very important 


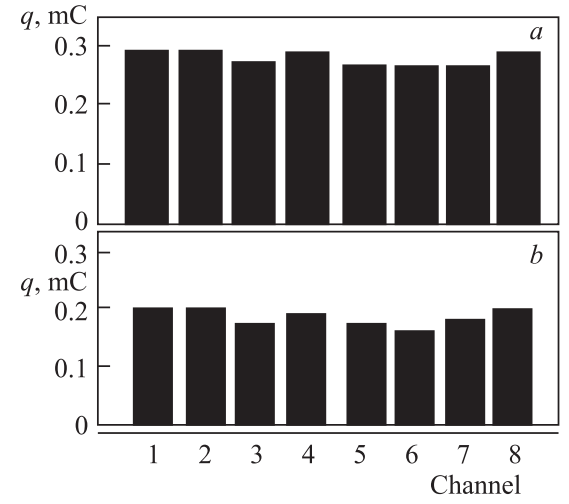

Fig. 2. Distribution of beam charges from each of the eight Faraday cup segments along the azimuth for the falling $(a)$ and uniform magnetic field $(b)$

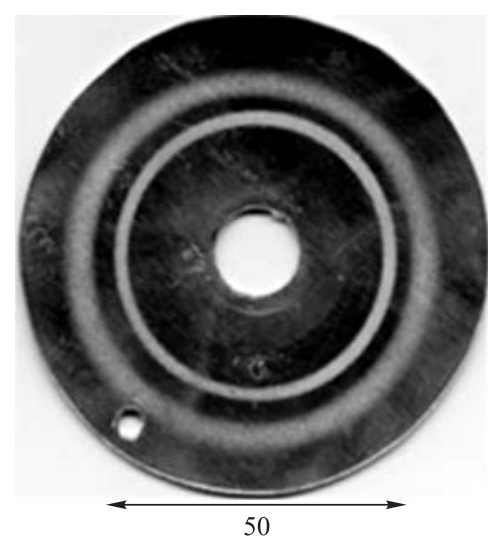

Fig. 3. Beam prints: 1 - falling magnetic field; 2 - rising magnetic field

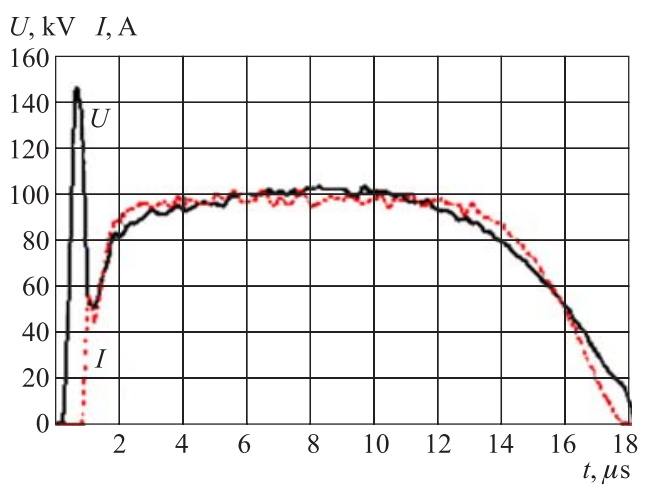

Fig. 4. Oscillograms of voltage pulses on the cathode $(U)$ and beam current $(I)$ in the falling magnetic field

when the accelerator with a magnetron gun is used for technological purposes, upon tuning the accelerator.

As a result of investigations, the modes of electron beam generation on the target were realized. The electron beam parameters for different modes in two accelerator gun geometries are given in Table 1.

Table 1

\begin{tabular}{|c|c|c|c|c|c|c|}
\hline $\begin{array}{c}\text { Electron } \\
\text { energy, keV }\end{array}$ & $\begin{array}{c}\text { Beam } \\
\text { current, A }\end{array}$ & $\begin{array}{c}\text { Pulse } \\
\text { duration, } \mu \mathrm{s}\end{array}$ & $\begin{array}{c}\text { Pulse repetition } \\
\text { rate, } \mathrm{Hz}\end{array}$ & $\begin{array}{c}\text { Power density on } \\
\text { the target, } \mathrm{MW} / \mathrm{cm}^{2}\end{array}$ & $\begin{array}{c}\text { Cathode, } \\
\mathrm{mm}\end{array}$ & $\begin{array}{c}\text { Anode, } \\
\mathrm{mm}\end{array}$ \\
\hline 42 & 50 & 6 & 15 & 0.6 & 40 & 70 \\
50 & 25 & 6 & 15 & 0.55 & 40 & 70 \\
60 & 68 & 22 & 3 & - & 40 & 78 \\
75 & 60 & 18 & 3 & 1,8 & 40 & 78 \\
100 & 110 & $\sim 15$ & 3 & 2,3 & 40 & 78 \\
\hline
\end{tabular}




\section{POSSIBLE APPLICATIONS OF AN ELECTRON BEAM PRODUCED BY THE ACCELERATOR}

1. Power electron beams may be used as one of effective methods for modification of surface properties of materials. The targets made of different materials were irradiated by the accelerator beam with parameters close to the optimum ones. In this case we used tool steel (U12M, KhVG, Kh12N), having the surface hardening property, and titanium. The parameters of the accelerator beam and targets before and after irradiation are given in Table 2 .

Table 2

\begin{tabular}{|c|c|c|c|c|c|}
\hline $\begin{array}{c}\text { Type of } \\
\text { material }\end{array}$ & $\begin{array}{c}\text { Electron } \\
\text { energy, keV }\end{array}$ & $\begin{array}{c}\text { Pulse } \\
\text { duration, } \mu \mathrm{s}\end{array}$ & $\begin{array}{c}\text { Power density on } \\
\text { the target, } \mathrm{MW} / \mathrm{cm}^{2}\end{array}$ & $\begin{array}{c}\text { Hardness before } \\
\text { treatment, } \mathrm{kg} / \mathrm{mm}^{2}\end{array}$ & $\begin{array}{c}\text { Hardness after } \\
\text { treatment, } \mathrm{kg} / \mathrm{mm}^{2}\end{array}$ \\
\hline Steel KhVG & 75 & 18 & 1.8 & 232 & 473 \\
Steel U12M & 75 & 18 & 1.8 & 232 & 550 \\
Steel Kh12N & 75 & 18 & 1.8 & 192 & 412 \\
Titanium & 75 & 18 & 1.8 & 148 & 210 \\
\hline
\end{tabular}

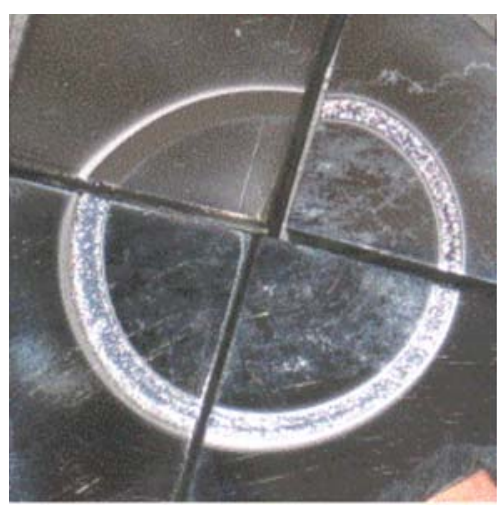

Fig. 5. Beam prints on the target device

Figure 5 shows a photograph of the beam print on the target assembly. The targets were irradiated under similar conditions in one and the same experiment, all the four specimens being fixed on the target device. The table shows that the steel hardness is doubled.

2. The beam produced by the accelerator may be used as an electron source in microwave devices, for example, in klystrons of a megawatt power. In this case the noise character of the secondary-emission multiplication and beam generation has a little influence on the processes in the electrodynamic structure, as in the case of voltage increasing the particle energy increases, and the particle energy spread is fixed and does not exceed several kilovolts [4]. On the other hand, the use of a tubular beam in the RF devices has some advantages.

Such a possibility has been studied in the course of developing the $3 \mathrm{~cm}$ RF source for the medical linear electron accelerator [5]. The most acceptable microwave RF power source for the compact accelerator is an amplifier klystron with a level of the output power from 1 to $2 \mathrm{MW}$, anode voltage of $50 \mathrm{kV}$. One of the methods used to decrease the beam density 
and to reduce the influence of spatial charge forces is the application of a hollow beam with a large diameter. To solve the problem, we have developed a cathode assembly for the electron source of the klystron based on the magnetron gun with a secondary-emission cathode [6]. At a cathode voltage of $50 \mathrm{kV}$ a tubular beam of $6 \mu$ s duration and $50 \mathrm{~A}$ amplitude was obtained. The external beam diameter was $\sim 50 \mathrm{~mm}$ with a wall thickness of $\sim 2 \mathrm{~mm}$ and the azimuthal beam homogeneity was $\pm 5 \%$. The beam current stability amplitude was $\sim 3 \%$ at a voltage amplitude instability of $\sim 2 \%$, using the hollow beam of a large diameter, the structure based on ring (coaxial) cavities can be applied as a cavity system.

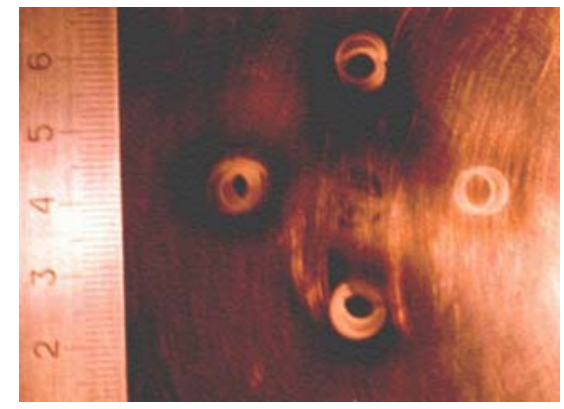

Fig. 6. Beam prints on the target

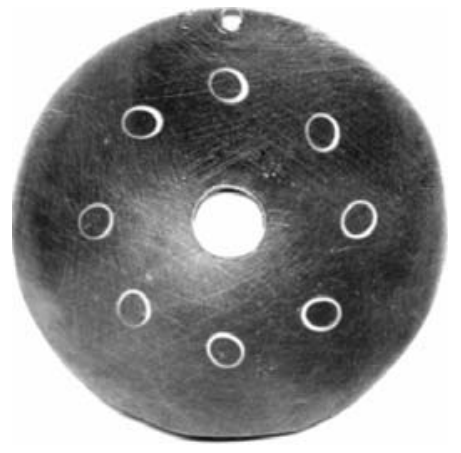

Fig. 7. Beam prints on the target

3. The investigations carried out have demonstrated that it is possible to control the electron beam cross section. Firstly, by changing the longitudinal magnetic field from the falling to rising one, or in the inhomogeneous electric field, the azimuthal homogeneity of a ring beam is changing up to the formation of a crescent-shaped cross section. Secondly, using the set of spatially located secondary-emission sources, it is possible to form electron beams in a given sequence. The prints of the four beams obtained in the multicathode source in the rectangular coordinate system are shown in Fig. 6 [7] and the prints of the eight beams obtained in the multicathode source in the cylindrical coordinate system are shown in Fig. 7 [8].

\section{CONCLUSION}

As a result of investigations on the electron beam formation using the accelerator based on a magnetron gun, we have achieved, in one of geometries, maximum operating conditions at which the beam current on the target is $\sim 110$ A with an energy of $\sim 100 \mathrm{keV}$ at a pulse duration of $15 \mu \mathrm{s}$. Such parameters permit us to reach a specific beam power of $\sim 2 \mathrm{MW} / \mathrm{cm}^{2}$. Thus, the electron beam produced by the accelerator can be used in the technological processes of material surface modification, as well as for the scientific research.

\section{REFERENCES}

1. Volkolupov Yu. Ya. et al. // Zh. Tekh. Fiz. 2001. V.71. P. 88 (in Russian).

2. Agaphonov A. V., Tarakanov V. P., Fedorov V. M. // Zh. Tekh. Fiz. 2004. V. 74 (in Russian). 
3. Dovbnya A. N. et al. // J. Kharkiv Nat. Univ. Ser. Phys. «Nuclei, Particles, Fields». 2004. V.642, issue 3(25). P.91-103 (in Russian).

4. Ayzatsky N. I. et al. // J. Kharkiv Nat. Univ. Ser. Phys. «Nuclei, Particles, Fields». 2001. V.522, issue 2 (14). P. 70 (in Russian).

5. Ayzatsky N. I. et al. // Probl. At. Sci. Technol. Ser. NPHI. 1999. V.3(34). P. 26 (in Russian).

6. Dovbnya A. N. et al. // Probl. At. Sci. Technol. Ser. NPHI. 2004. V. 1(42). P. 122.

7. Ayzatsky N. I. et al. // Pis'ma Zh. Tekh. Fiz. 2001. V.27, No. 23. P. 25 (in Russian).

8. Ayzatsky N. I. et al. // Zh. Tekh. Fiz. 2003. V.73. P. 113 (in Russian). 